\title{
SPECTROPHOTOMETRIC ANALYSIS OF THE RESAZURIN REDUCTION TEST AS A TOOL FOR ASSESSING CANINE SEMEN QUALITY
}

\author{
RAFAŁ STRZEŻEK, KRYSTYNA FILIPOWICZ, \\ MARTA STAŃCZAK, AND WŁADYSŁAW KORDAN

\begin{abstract}
Department of Animal Biochemistry and Biotechnology, Faculty of Animal Bioengineering, University of Warmia and Mazury in Olsztyn, 10-718 Olsztyn, Poland rafi@uwm.edu.pl
\end{abstract}

Received: December 7, 2012

Accepted: May 3, 2013

\begin{abstract}
The resazurin reduction test (RRT) was subjected to spectrophotometric analysis to evaluate the quality of canine semen. Twenty four samples of canine semen were analysed. The absorption peaks for resazurin and resorufin were determined at 615 and $580 \mathrm{~nm}$, respectively. The RRT ratio $\left(\mathrm{RRT}_{\text {sperm}}\right.$-the ratio for samples containing spermatozoa, $\mathrm{RRT}_{\text {plasma }}$-the ratio for samples containing seminal plasma) was calculated by dividing the absorbance at $580 \mathrm{~nm}$ by the absorbance at $615 \mathrm{~nm}$. Spearman's correlation test was used to determine the significance of correlations between the analysed sperm parameters and the results of the resazurin reduction assay. The RRT ratio was highly correlated with sperm motility $(\mathrm{r}=0.68, \mathrm{P}<0.01)$, progressive sperm motility $(\mathrm{r}=0.61, \mathrm{P}<0.01)$, the subpopulation of cells with rapid velocity $(\mathrm{r}=0.72, \mathrm{P}<0.01)$, and the subpopulation of cells with medium velocity $(\mathrm{r}=-0.54, \mathrm{P}<0.05)$. A negative correlation was observed between the reducing capacity of seminal plasma $v s$. sperm with plasma membrane integrity $(\mathrm{r}=-0.60, \mathrm{P}<0.01)$ and sperm with normal morphology $(\mathrm{r}=-0.58, \mathrm{P}<0.01)$. The RRT test can be used as an additional tool for evaluation of the quality of canine semen.
\end{abstract}

Key words: dog, semen, resazurin assay, quality of semen.

Resazurin is a popular redox dye used in examinations of bacterial and yeast contamination of milk (6). In oxidized form, the dye has a blue colour. Following a reaction with oxidoreductase enzymes from metabolically active cells, resazurin is reduced to pinkcoloured resorufin and, subsequently, to colourless hydroresorufin $(2,6)$.

The resazurin reduction test (RRT) supports the identification of metabolically active spermatozoa (13). It has been used in semen evaluations in humans $(3,4,7$, 13), bulls (2), rams (11), stallions (1), and boars (15). Initially, resazurin reduction tests involved a visual detection of colour change $(1,2)$. Due to the risk of human error, the resazurin reduction test was modified spectrophotometrically $(13,15)$.

The aim of the study was to evaluate the accuracy of the resazurin reduction test by spectrophotometric analysis in assessments of canine semen quality.

\section{Material and Methods}

Ejaculate collections. Semen was collected from four mixed-breed dogs (aged 2-6 years), marked A, $\mathrm{B}, \mathrm{C}$, and D, once a week for 6 weeks. Sperm concentrations were determined cytometrically using a haemocytometer. The dogs were housed in individual pens and fed a commercial canine feed. Water was available ad libitum. Animal experiments were carried out in accordance with the guidelines set out by the Local Ethics Committee.

Preparation of spermatozoal pellets and seminal plasma. Semen samples containing $50 \times 10^{6}$ spermatozoa were centrifuged at $700 \times \mathrm{g}$ for $5 \mathrm{~min}$. Seminal plasma was removed from the sperm pellet, transferred to a new centrifuge tube, and centrifuged repeatedly $(10,000 \times \mathrm{g}$ for $10 \mathrm{~min})$. The sperm pellet remaining after the removal of seminal plasma was resuspended in physiological saline solution $(0.9 \%$ $\mathrm{NaCl})$.

Spectrophotometric assessment of resazurin dye reduction. Specific absorbance wavelengths of resazurin and resorufin were determined before the assay. $12.5 \mu \mathrm{L}$ of resazurin solution $(2 \mathrm{mM}$ resazurin saline solution) was added to each sample of sperm and seminal plasma, and the samples were incubated at $37^{\circ} \mathrm{C}$. When the samples turned completely pink, $1.2 \mathrm{~mL}$ of n-butyl alcohol was added, and the samples were vortexed. The control sample (blue colour solution) was prepared by adding n-butanol immediately after resazurin. After centrifugation, blue (resazurin) and pink 
(resorufin) solutions were separated from the clear upper layers of n-butanol, and they were scanned in the range of $400 \mathrm{~nm}$ to $700 \mathrm{~nm}$ against n-butanol as a blank sample with the use of a spectrophotometer (DU-800, Beckman Coulter Inc, USA). Two major sensitive peaks were determined at $615 \mathrm{~nm}$ (resazurin) and $580 \mathrm{~nm}$ (resorufin).

Assay procedure. The resazurin reduction test was performed according to the method described by Zalata et al. (13) with some modifications. The volume of $12.5 \mu \mathrm{L}$ of resazurin solution $(2 \mathrm{mM}$ resazurin saline solution) was added to samples containing $50 \times 10^{6}$ spermatozoa and $0.5 \mathrm{~mL}$ of seminal plasma. The samples were incubated at $37^{\circ} \mathrm{C}$. After $60 \mathrm{~min}, 1.2 \mathrm{~mL}$ of n-butanol was added, and the samples were centrifuged $(700 \times \mathrm{g}$ for $10 \mathrm{~min})$. After centrifugation, alcohol supernatant was transferred to a vial and absorbance was determined at a wavelength of $580 \mathrm{~nm}$ (specific absorbance wavelength of resorufin) and 615 $\mathrm{nm}$ (specific absorbance wavelength of resazurin). The obtained values were compared with control samples containing n-butanol. The RRT ratio $\left(\mathrm{RRT}_{\text {sperm }}\right.$-ratio for samples containing spermatozoa, $\mathrm{RRT}_{\text {plasma }}$-ratio for samples containing seminal plasma) was calculated by dividing the absorbance at $580 \mathrm{~nm}$ by the absorbance at $615 \mathrm{~nm}$, according to the method described by Reddy and Bordekar (7).

Evaluation of sperm parameters. Sperm motility characteristics were evaluated using the Hamilton-Thorne Sperm Analyzer IVOS version 12.3 (Hamilton-Thorne Biosciences, USA). The software settings for the semen analyser were those recommended by the manufacturer for analysis of dog sperm: frame acquired 30, frame rate $60 \mathrm{~Hz}$, minimum cell contrast 75 , minimum cell size 6 pixels, straightness threshold $75 \%$, path velocity threshold $100 \mu \mathrm{m} / \mathrm{s}$, low VAP cut-off $9.9 \mu \mathrm{m} / \mathrm{s}$, low VSL cut-off $20 \mu \mathrm{m} / \mathrm{s}$, static size gates $0.80-4.93$, static intensity gates $0.49-1.68$, static elongation gates 22-84. A droplet of approximately $5 \mu \mathrm{L}$ was placed in a Makler counting chamber (SefiMedical Instruments Ltd., Israel) at $37^{\circ} \mathrm{C}$, and six fields were examined per sample. The motility parameters determined by the IVOS analyser were: total motility (MOT, \%), progressive motility (PMOT, \%), subpopulation of RAPID (\%), MEDIUM (\%), SLOW $(\%)$, and STATIC cells.

Sperm plasma membrane integrity (SPMI) was assessed by the dual fluorescent staining technique described by other authors (5), using SYBR-14 and propidium iodide, PI (Live/Dead Sperm Viability Kit; Molecular Probes, USA). Aliquots $(10 \mu \mathrm{L})$ of stained sperm samples were examined under an epifluorescence microscope (Olympus CH 30, Japan). For each aliquot, approximately 200 sperm cells were classified as spermatozoa with intact or damaged plasma membrane.

Mitochondrial membrane potential (MMP) was assessed in sperm aliquots using a dual fluorescent staining technique with $5,5^{\prime}, 6,6$ '-tetrachloro-1,1',3,3'tetraethylbenzimidazolylcarbo-cyanineiodide (JC-1) (1 $\mathrm{mg} / \mathrm{mL}$ DMSO) (Molecular Probes, USA) and PI ( $10 \mu \mathrm{L}$ of PI solution in $0.5 \mathrm{mg} / \mathrm{mL}$ PBS), according to a previously described method (10). Aliquots $(10 \mu \mathrm{L})$ of stained sperm samples were examined under an epifluorescence microscope (Olympus CH 30, Japan). Sperm cells displaying only orange-red fluorescence at the mid-piece region were considered viable spermatozoa with high MMP.

Sperm morphology was assessed by staining sperm smears with the Giemsa staining method according to Watson (12). Morphological abnormalities were expressed as percentage of the total number of all counted spermatozoa.

The ATP content in spermatozoa was assessed using a bioluminescence kit (ATP Bioluminescence Assay Kit CLSII; Roche Molecular Biochemical). Measurements of ATP content were performed using a Junior Bioluminometer (Berthold Technologies, Germany), according to the assay kit protocol. The ATP content in spermatozoa was calculated from an ATP standard curve and expressed as nmol ATP $/ 10^{8}$ spermatozoa.

Statistical analysis. All values were expressed as the means \pm standard deviation (SD). The data was analysed by ANOVA and Duncan's multiple comparison test using the Statistica software package (StatSoft Incorporation, USA). Differences between means were regarded as significant at $\mathrm{P} \leq 0.05$. Spearman's correlation test was used to determine significant correlations between the results of the resazurin reduction test and the analysed sperm parameters.

\section{Results}

The absorbance values for resorufin and resazurin, and the values of the RRT ratio determined in sperm and seminal plasma samples are presented in Table 1.

Significant differences in the RRT ratio for sperm samples $\left(\mathrm{RRT}_{\text {sperm }}\right)$ were observed between individuals. The highest value of $\mathrm{RRT}_{\text {sperm }}$ was reported in sperm samples obtained from $\operatorname{dogs} \mathrm{A}$ and $\mathrm{C}$. The above ejaculates were also characterised by the highest values of MOT, PMOT, RAPID, and SPMI (Table 2). The RRT ratio for seminal plasma samples ( RRT $_{\text {plasma }}$ ) was lower $(0.81$ to 3.0$)$ than $\mathrm{RRT}_{\text {sperm. Seminal plasma }}$ samples from $\operatorname{dog} B$ revealed the highest value of $\mathrm{RRT}_{\text {plasma. }}$ The above ejaculate was also characterised by the lowest percentage of sperm cells with normal morphology (Table 2). Significant positive correlations were observed between $\mathrm{RRT}_{\text {sperm }}$ and MOT, PMOT, RAPID, and a negative correlation was reported with the subpopulation of MEDIUM sperm cells (Table 3). $\mathrm{RRT}_{\text {plasma }}$ was negatively correlated with SPMI $(-0.60, \mathrm{P}<0.01)$ and morphologically normal sperm cells $(-0.58, \mathrm{P}<0.01)$. 
Table 1

Spectrophotometric analysis of resazurin and resorufin levels and the RRT ratio in sperm and seminal plasma samples ( $\mathrm{n}=24)$

\begin{tabular}{ccccccc}
\hline \multirow{2}{*}{ Dog } & \multicolumn{3}{c}{ Sperm } & \multicolumn{3}{c}{ Seminal plasma } \\
\cline { 2 - 7 } & $\begin{array}{c}\text { Absorbance } \\
(\mathrm{nm}) 580\end{array}$ & $\begin{array}{c}\text { Absorbance } \\
(\mathrm{nm}) 615\end{array}$ & $\mathrm{RRT}_{\text {sperm }}$ & $\begin{array}{c}\text { Absorbance } \\
(\mathrm{nm}) 580\end{array}$ & $\begin{array}{c}\text { Absorbance } \\
(\mathrm{nm}) 615\end{array}$ & RRT $_{\text {plasma }}$ \\
\hline \multirow{2}{*}{$\mathrm{A}$} & 0.469 & 0.082 & 5.71 & 0.375 & 0.458 & 0.81 \\
& $\pm 0.03^{\mathrm{a}}$ & $\pm 0.004^{\mathrm{a}}$ & $\pm 0.17^{\mathrm{a}}$ & \pm 0.02 & $\pm 0.033^{\mathrm{a}}$ & $\pm 0.03^{\mathrm{a}}$ \\
\hline \multirow{2}{*}{$\mathrm{B}$} & 0.452 & 0.117 & 3.86 & 0.406 & 0.134 & 3.02 \\
& $\pm 0.014^{\mathrm{a}}$ & $\pm 0.008^{\mathrm{b}}$ & $\pm 0.14^{\mathrm{b}}$ & \pm 0.094 & $\pm 0.087^{\mathrm{b}}$ & $\pm 1.06^{\mathrm{b}}$ \\
\hline \multirow{2}{*}{$\mathrm{C}$} & 0.443 & 0.099 & 4.47 & 0.366 & 0.204 & 1.79 \\
& $\pm 0.021^{\mathrm{a}}$ & $\pm 0.004^{\mathrm{a}}$ & $\pm 0.36^{\mathrm{ab}}$ & \pm 0.047 & $\pm 0.08^{\mathrm{bc}}$ & $\pm 0.8^{\mathrm{b}}$ \\
\hline \multirow{2}{*}{$\mathrm{D}$} & 0.347 & 0.086 & 4.03 & 0.369 & 0.302 & 1.22 \\
& $\pm 0.041^{\mathrm{b}}$ & $\pm 0.009^{\mathrm{a}}$ & $\pm 0.83^{\mathrm{b}}$ & \pm 0.028 & $\pm 0.077^{\mathrm{ac}}$ & $\pm 0.84^{\mathrm{ab}}$ \\
\hline
\end{tabular}

Values represent the means ( \pm SEM) of six ejaculates, each from four dogs. Values with different superscripts $(\mathrm{a}, \mathrm{b}, \mathrm{c})$ are significant at $\mathrm{P}<0.05$, within columns

Table 2

Microscopic and biochemical characteristics of selected sperm parameters $(n=24)$

\begin{tabular}{|c|c|c|c|c|c|c|c|c|c|}
\hline \multirow{2}{*}{ Dog } & \multicolumn{5}{|c|}{ Sperm motility parameters } & \multirow{2}{*}{$\begin{array}{l}\text { SPMI } \\
(\%)\end{array}$} & \multirow{2}{*}{$\begin{array}{l}\text { MMP } \\
(\%)\end{array}$} & \multirow{2}{*}{$\begin{array}{c}\text { Sperm with } \\
\text { normal } \\
\text { morphology } \\
(\%)\end{array}$} & \multirow{2}{*}{$\begin{array}{c}\text { ATP content } \\
\left(\mathrm{nmol} / 10^{8} \text { sperm }\right)\end{array}$} \\
\hline & $\begin{array}{l}\text { MOT } \\
(\%)\end{array}$ & $\begin{array}{l}\text { PMOT } \\
(\%)\end{array}$ & $\begin{array}{l}\text { RAPID } \\
(\%)\end{array}$ & $\begin{array}{l}\text { MEDIUM } \\
(\%)\end{array}$ & $\begin{array}{l}\text { SLOW } \\
(\%)\end{array}$ & & & & \\
\hline A & $93.8 \pm 0.8^{\mathrm{a}}$ & $73.0 \pm 1.5$ & $85.6 \pm 2.2^{\mathrm{a}}$ & $8.0 \pm 1.5^{\mathrm{a}}$ & $4.0 \pm 0.2^{\mathrm{a}}$ & $87.5 \pm 1.9$ & $82.5 \pm 1.5$ & $89.3 \pm 2.4^{\mathrm{a}}$ & $4.5 \pm 0.5^{\mathrm{a}}$ \\
\hline $\mathrm{B}$ & $90.5 \pm 1.2^{\mathrm{ab}}$ & $69.0 \pm 2.5$ & $77.7 \pm 1.4^{\mathrm{bc}}$ & $12.4 \pm 1.1^{\mathrm{b}}$ & $5.7 \pm 0.9^{\mathrm{ab}}$ & $84.2 \pm 2.4$ & $84.8 \pm 1.3$ & $73.4 \pm 1.7^{\mathrm{b}}$ & $6.4 \pm 0.8^{\mathrm{b}}$ \\
\hline $\mathrm{C}$ & $94.8 \pm 0.7^{\mathrm{a}}$ & $71.0 \pm 0.6$ & $83.4 \pm 0.7^{\mathrm{ab}}$ & $11.4 \pm 0.6^{\mathrm{a}}$ & $2.8 \pm 0.2^{\mathrm{a}}$ & $86.0 \pm 2.5$ & $84.4 \pm 1.1$ & $93.0 \pm 1.1^{\mathrm{ac}}$ & $5.9 \pm 0.9^{\mathrm{ab}}$ \\
\hline $\mathrm{D}$ & $88.4 \pm 2.3^{\mathrm{b}}$ & $67.8 \pm 2.4$ & $74.0 \pm 3.2^{\mathrm{c}}$ & $11.8 \pm 1.7^{\mathrm{a}}$ & $7.6 \pm 1.7^{\mathrm{b}}$ & $85.8 \pm 2.8$ & $81.4 \pm 3.3$ & $94.6 \pm 0.5^{\mathrm{c}}$ & $4.3 \pm 1.0^{\mathrm{a}}$ \\
\hline
\end{tabular}

Values represent the means $( \pm \mathrm{SEM})$ of six ejaculates, each from four dogs. Values with different superscripts $(\mathrm{a}, \mathrm{b}, \mathrm{c})$ are significant at $\mathrm{P}<0.05$, within columns. MOT -

percentage of total motile sperm, PMOT - percentage of progressively motile sperm, RAPID - subpopulation of cells with rapid velocity, MEDIUM - subpopulation of cells with medium velocity, SLOW - subpopulation of cells with slow velocity, SPMI - sperm plasma membrane integrity, MMP - mitochondrial membrane potential 
Table 3

Correlations between the RRT ratio of spermatozoa and sperm motility characteristics (rank correlation)

\begin{tabular}{ccc}
\hline $\begin{array}{c}\text { Sperm } \\
\text { motility } \\
\text { characteristics }\end{array}$ & $\begin{array}{c}\text { Correlation } \\
\text { coefficient (r) }\end{array}$ & Significance (P) \\
\hline MOT & 0.68 & $<0.01$ \\
\hline PMOT & 0.61 & $<0.01$ \\
\hline RAPID & 0.72 & $<0.01$ \\
\hline MEDIUM & -0.54 & $<0.05$ \\
\hline
\end{tabular}

\section{Discussion}

Measurements of resazurin reduction support the identification of metabolically active spermatozoa (13). In the study, the spectrophotometric method was applied for the first time to analyse canine semen. RRT was performed separately for spermatozoa and seminal plasma samples. In a study of human semen, Zalata et al. (13) observed the maximum absorption of resazurin at a wavelength of $615 \mathrm{~nm}$ and the maximum absorption of its reduced form, resorufin at $580 \mathrm{~nm}$. In the conducted experiment, absorbance peaks for resazurin and resorufin were reported at identical wavelengths for spermatozoa and seminal plasma samples. In line with the method proposed by Reddy and Bordaker (7), the RRT ratio was regarded as a measure of resazurin (unreacted) levels and dye concentrations, which were reduced to resorufin.

In most studies analysing the use of RRT in evaluations of semen quality, separate tests were not performed for spermatozoa and seminal plasma (3, 4, 13). In this experiment, the tested sample contained $50 \times 10^{6}$ spermatozoa because samples containing more than $50 \times 10^{6}$ sperm cells are burdened by significant risk of false positive results, which can probably be related to a very high rate of reduction reactions (8).

The reliability of RRT in semen evaluations is also determined by the time of sample incubation. Zalata et al. (13) incubated human sperm cells and seminal plasma for $2 \mathrm{~h}$. In a study by Zrimsek et al. (15), whole boar semen was incubated with resazurin for around 30 min. In this experiment, semen and seminal plasma samples were incubated with a resazurin solution for $1 \mathrm{~h}$. After this time, the colour of all sperm samples changed from blue to various shades of pink. Changes in the colour of seminal plasma samples were less decisive.

Significant correlations were observed between $\mathrm{RRT}_{\text {sperm }}$ and motility parameters, and the results are consistent with other authors' findings. In a study of human semen, Mahmound et al. (4) found significant correlations between RRT results and sperm cell concentrations $\quad(\mathrm{r}=0.70, \quad \mathrm{P}<0.001), \quad$ as well as concentrations of motile spermatozoa $(\mathrm{r}=0.65, \mathrm{P}<0.001)$. In the work of Reddy and Bordekar (7), the RRT ratio of human semen was significantly correlated with the percentage of motile sperm cells $(\mathrm{r}=0.889, \mathrm{P}<0.001)$.

In the study, no significant correlations were found between $\mathrm{RRT}_{\text {sperm }}$ and the ATP content of sperm. In the available literature, significant correlations between RRT results and ATP levels in human semen $(\mathrm{r}=0.65, \mathrm{P}<0.001)$ were observed only by Mahmound et al. (4). The cited authors did not provide an interpretation of the above result.

In general, RRT results seem to illustrate the rate of reduction processes in sperm cells rather than ATP synthesis. During metabolic processes (glycolysis/fructolysis, pentose phosphate pathway, and tricarboxyl acid cycle), motile sperm produce reducing equivalents (such as $\mathrm{NAPH}+\mathrm{H}^{+}$and $\mathrm{NADH}+\mathrm{H}^{+}$). The presence of reducing nucleotides in sperm cells is an indicator of their metabolic activity (13). It has been also suggested that diaphorases, NAD(P)-dependent enzymes, are responsible for the reduction of resazurin to resorufin $(6,13)$. Diaphorases were found to be active in the sperm cells of humans and many animal species, in particular in midpiece region, which further testifies to their significant role in resazurin reduction (13). According to Zalata et al. (13), the addition of $\mathrm{NADH}+\mathrm{H}^{+}$to a sperm or seminal plasma suspension significantly intensifies resazurin reduction.

The mechanism behind the reducing ability of seminal plasma has not been completely explained. Sperm with abnormal morphology could be the source of reducing nucleotides and/or nucleotide-dependent enzymes in seminal plasma (13). NAD(P)-dependent diaphorases were found to be highly active in the cytoplasmic droplets of human spermatozoa (14). In the experiment, this was confirmed by the fact that the ejaculate of $\operatorname{dog} \mathrm{B}$, characterised by the highest value of

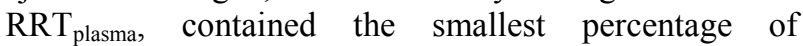
morphologically normal sperm cells and considerable percentage of sperm with cytoplasmic droplets (data not shown). Negative correlations were determined between $\mathrm{RRT}_{\text {plasma }}$ vs. SPMI and sperm with normal morphology. Mahmound et al. (4) reported the presence of several reducing substances in seminal plasma, including L-ascorbic acid and L-glutathione. In our previous study of antioxidant systems in canine semen, significant levels of the discussed substances in the seminal plasma of dogs were observed (9).

It can be concluded that the evaluation of RRT results by the spectrophotometric method may provide more accurate information on the quality of canine semen.

Acknowledgements: This study was supported by research grant No. 0103.0803.

\section{References}

1. Carter R.A., Ericsson S.A., Corn C.D., Weyerts P.R., Dart M.G., Escue S.G., Mesta J.: Assessing the fertility potential of equine semen samples using the reduction dyes methylene green and resazurin. Arch Androl 1998, 40, 59-66.

2. Dart M.G., Mesta J., Cremshaw C., Ericsson S.A.: Modified resazurin test for determining the fertility potential of bovine spermatozoa. Arch Androl 1994, 33, 71-75.

3. Glass R.H., Ericsson S.A., Ericsson R.J., Drovin M.T., Marcoux L.J., Sullivan J.: The resazurin reduction test provides an assessment of sperm activity. Fert Steril 1991, 56, 743-746. 
4. Mahmoud A.M., Comhaire F.H., Vermeulen L., Andreou E.: Comparison of the resazurin test, adenosine triphosphate in semen and various sperm parameters. Hum Reprod 1994, 9, 1688-1693.

5. Niżański W., Partyka A., Rijsselaere T.: Use of fluorescent stainings and flow cytometry for canine semen assessment. Reprod Dom Anim 2012, 47, Suppl 6, 215-221.

6. O'Brien J., Wilson I., Orton T., Pognan F.: Investigation of the Alamar Blue (resazurin) fluorescent dye for the assessment of mammalian cell cytotoxicity. Eur J Biochem 2000, 267, 5421-5426.

7. Reddy K.V., Bordekar A.D.: Spectrophotometric analysis of resazurin reduction test and semen quality in men. Indian J Exp Biol 1999, 37, 782-786.

8. Strzeżek R., Filipowicz K., Stańczak M.: Comparison of sperm motility parameters with resazurin reduction assay. Acta Biochim Pol 2012, 59, Suppl 3, 152.

9. Strzeżek R., Koziorowska-Gilun M., Kowalówka M., Strzeżek J.: Characteristics of antioxidant system in dog semen. Pol J Vet Sci 2009, 12, 55-60.

10. Thomas C.A., Garner D.L., DeJarnette J.M, Marshall C.E.: Effect of cryopreservation on bovine sperm organelle function and viability as determined by flow cytometry. Biol Reprod 1998, 58, 786-793.

11. Wang S., Holyoak G.R., Panter K.E., Liu Y., Evans R.C., Bunch T.D.: Resazurin reduction assay for ram sperm metabolic activity measured by spectrophotometry. Proc Soc Exp Biol Med 1998, 217, 197-202.

12. Watson P.F.: Use of Giemsa stain to detect changes in acrosomes of frozen ram spermatozoa. Vet Rec 1975, 97, 12-13.

13. Zalata A.A., Lammertijn N., Christoper A., Comhaire F.H.: The correlates and alleged biochemical background of the resazurin reduction test in semen. Int J Androl 1998, 21, 289-294.

14. Zini A., O'Bryan M.K., Israel L., Schlegel P.N.: Human sperm NADH and NADPH diaphorase cytochemistry: correlation with sperm motility. Urology 1998, 51, 464468.

15. Zrimsek P., Kurc J., Kosec M., Mrkun J.: Spectrophotometric application of resazurin reduction assay to evaluate boar semen quality. Int J Androl 2004, 27, 57-62. 